\title{
Process evaluation of two environmental nutrition programs and an educational nutrition program conducted at supermarkets and worksite cafeterias in the Netherlands
}

keywords: process evaluation, nutrition, education, labeling, supermarkets, worksite cafeterias

Ingrid Steenhuis ${ }^{* 1}$

Patricia van Assema ${ }^{* 2}$

Astrid Reubsaet $^{* 2}$

Gerjo Kok ${ }^{* 3}$

name of institute where the work was undertaken:

Department of Health Education and Promotion, Maastricht University, P.O. Box 616, 6200 MD

Maastricht, The Netherlands.

Published as:

Steenhuis, I.H.M., Assema, P. van, Reubsaet, A. \& Kok. G. (2004). Process evaluation of two environmental nutrition programmes and an educational nutrition programme conducted at supermarkets and worksite cafeterias in the Netherlands. Journal of Human Nutrition and Dietetics. 17, 107-115. 


\begin{abstract}
Introduction

This article describes the process evaluation of two environmental programs and a educational nutrition program, implemented at supermarkets and worksite cafeterias. Studies conducted earlier, indicated that the programs had no effect on consumers' eating behavior. Consequently, the more specific purpose of the present study was to identify explanations for the ineffectiveness of the programs and to formulate recommendations for future programs.
\end{abstract}

\title{
Materials and Methods
}

The environmental programs included labeling of healthy products and increasing the range of healthy foods on offer. The education program consisted of several elements, such as brochures and a self-help guide. Semi-structured interviews were conducted with twenty-one managers of supermarkets and worksite cafeterias where the programs were implemented.

\section{Results}

Although materials were not always entirely compatible with the different supermarkets and worksite cafeterias, the degree of implementation was satisfactory. According to the managers, the programs were not striking enough, the labeling would have been more effective if it had discriminated between different brands of a product, and the number of new products was too small compared to the total range of foods on offer.

\section{Discussion}

The results can be used to help design and check future intervention programs for use at supermarkets or worksite cafeterias. Recommendations for future programs and research are given. 


\section{Introduction}

Dietary factors have been found to be important in the prevention of cancer and coronary heart disease, for example the consumption of fat, fruit and vegetables (Willet, 1994). For years now, the official Dutch Guidelines for Healthy Nutrition have recommended reducing one’s dietary fat intake (Health Council of the Netherlands, 2001). The Netherlands Bureau for Food and Nutrition also recommends to eat ample amounts of fruits and vegetables (Netherlands Bureau for Food and Nutrition, 1992). However, there is still a discrepancy between these guidelines and the actual intake of the Dutch population (Netherlands Bureau for Food and Nutrition, 1998).

Nutrition education methods combined with environmental interventions may help consumers meet the guidelines for a healthy diet. Environmental interventions can be defined as strategies that reduce barriers or increase opportunities for healthy choices, i.e. by creating more healthy choices, making them more accessible (convenient to find and not too expensive), and establishing policies that require healthy options to be available or which limit the number of less healthy ones (Glanz, 1993).

Environmental interventions aimed at changing dietary habits include nutritional labeling, regulation of health claims, shelf labeling in supermarkets, changes in food preparation or the food on offer at places where food is prepared, served or sold, catering policies and pricing policies. The focus of this article is on two environmental strategies: labeling (in supermarkets and worksite cafeterias) and increasing the range of healthy foods (in worksite cafeterias).

In the past, various studies have been conducted into the effectiveness of labeling in worksite cafeterias and supermarkets (for example Kristal et al., 1997; Lang et al., 2000; Patterson et al., 1992; Probart, 1993). Some studies were aimed at fat, fruit or vegetable intake, while others were targeted at increasing fiber intake or decreasing cholesterol, sugar or sodium intake. Some studies showed an effect, for example on sales numbers of low fat meals or products (Levin, 1996; Patterson et al., 1992) or on consumption (Sorenson et al., 1992), other studies did not show any effects of the labeling (Kristal et al., 1997; Mayer et al., 1987). Not many studies have been conducted into the effectiveness 
of increasing the range of foods available at worksite cafeterias. Mixed effects were found in the two studies conducted: for some nutrients or food products, significant effects were found (sodium, fruit and salad), while for others no effects were observed (fat, cholesterol) (Jeffery et al., 1994; Schmitz \& Fielding, 1986). Thus, previous studies into the effectiveness of labeling and increasing the range of healthy foods show mixed results, and show that it is not yet clear whether these interventions are effective.

In order to gain a better understanding of the effectiveness of environmental interventions, we developed a labeling program and a program including an enlargement of the assortment of healthy foods, to be combined with a general nutrition education program. The programs were aimed at reducing fat intake and increasing fruit and vegetable intake. The behavioral effects of the educational intervention alone and the educational intervention combined with the environmental intervention were assessed in experiments in supermarkets and worksite cafeterias (see also Steenhuis et al., in press (a); Steenhuis et al., in press (b). Seventeen worksite cafeterias and thirteen supermarkets participated in the studies. Both studies used a randomized pretest-posttest experimental control group design. Besides a control condition with no program, the studies included a condition with a nutrition education program only and conditions with an educational program combined with an environmental component (labeling or an increased range of healthy foods). In both studies, no significant effects on consumption data were found for any of the programs in either study. Sales data collected at the worksite cafeterias revealed a significant effect of the labeling program where the consumption of desserts was concerned, but not for the other products.

A possible explanation for the ineffectiveness of the interventions was the low level of perceived personal relevance of the programs. Process evaluation data from both studies also showed that awareness of the program materials used at the worksites and supermarkets was not very high, especially awareness of the environmental program components (Steenhuis et al., in press (a); Steenhuis et al., in press (b). 
This article will describe the process evaluation which was held with the managers of the supermarkets and worksite cafeterias where the interventions were implemented. Goal is to identify other possible reasons for the ineffectiveness of the nutrition education program and the environmental components.

\section{Materials and Methods}

\section{Intervention}

The interventions were developed on the basis of the results of a preliminary study of the conditions for adoption and implementation of nutrition programs at worksite cafeterias and supermarkets (Steenhuis et al., 2001). The results of this study indicated that programs for worksite cafeterias should not be too obtrusive or dominant, should not consume too much of the personnel's or customers' time, and should emphasize the positive aspects. Furthermore, labeling should only be used for healthy products and labels should be hygienic and easily comprehensible. In increasing the range of products available, it was important that prices should not increase, and only limited changes to the range were desirable. In general, the same factors were important for supermarkets. The importance of increasing profits and the need for program materials to be professionally and attractively produced were additional factors requiring consideration in supermarket programs. Where the labeling was concerned, one specific point for the supermarkets was that it was not possible to label too many products. Labeling should therefore be restricted to the most important product categories, and shelf labeling should be used instead of labeling each individual product. All these factors were taken into account in the development and design of the final interventions.

The intervention program ran for two months (supermarkets) or one month (worksite cafeterias) and could be prolonged by the managers up to six months (all managers agreed to extend the programs). The range of food products available was only increased at the worksite cafeterias, since most supermarkets already offered an extensive range of healthy products. The content of the programs used 
at the supermarkets and worksite cafeterias was almost identical, but some of the program materials were designed differently. The intervention programs were pretested among managers of supermarkets and worksite cafeterias and consumers. On the basis of the pretest results, parts of the intervention were refined. The research team assisted with the implementation of the programs at the supermarkets and worksite cafeterias. Personnel were informed about the programs at a special meeting organized by the research team. A program manual was also available for all supermarkets and worksites participating in the study.

\section{Nutrition education program}

The nutrition education program targeted important determinants for eating less fat and more fruit and vegetables, including awareness of personal consumption levels, attitudes towards eating less fat and more fruit and vegetables, social influences on healthy eating habits, self-efficacy, and skills for selecting and preparing low-fat products/meals and eating 2 pieces of fruit and 200 grams of vegetables a day (see also Brug, 2000). The program consisted of various elements. Of these, some were optional for the supermarkets and worksites participating in the study, while others were basic elements and therefore obligatory. For supermarkets, the basic elements were posters, brochures, recipe cards and a free self-help manual, which could be obtained by filling in a coupon included in the brochure. Optional elements included badges for supermarket personnel, "Next Customer” bars on checkout conveyer belts bearing the program logo and slogan (“eat less fat”) and a contest with questions about healthy nutrition. For worksites, the recipe cards were replaced by table-top information stands, and an article in the worksite newsletter was added to the optional elements.

\section{Labeling program}

The goal of the labeling was to make healthy choices visible and easily recognizable. Low-fat products in various food product categories, such as meat and meat products or milk and dairy products, were labeled with a shelf label (supermarkets), or a sign in front of the product (worksite cafeterias). The information on the label consisted of the program logo, the name of the item, and a statement that the 
product was a low-fat product. At the worksite cafeterias, fruit and vegetables were also labeled with a sign in front of the products.

\section{Increased range of food products}

The range of low-fat products and of fruit and vegetables at worksite cafeterias was increased by at least four products, for example low-fat cheese or a low-fat snack. Attention was drawn to the new products by a sign placed in front of them, bearing the words "new and healthy".

\section{Interview topics}

Data were gathered by means of interviews. The interview questions concerned the implementation of the programs, managers' opinions on the various program elements and program organization, and the reactions of customers as perceived by the managers. The main interview topics are listed in Table 1. Identical interview schemes were used for the worksites and the supermarkets.

\section{Procedures of research}

Semi-structured interviews were conducted with the managers of the supermarkets and worksite cafeterias where the intervention was implemented. The interviews were held two months (supermarkets) or one month (worksite cafeterias) after the start of the intervention. They lasted approximately 45 minutes. The supermarkets belonged to various regional or national chains, and some of them were franchises. The cafeterias included in the study belonged to large Dutch companies and government organizations with mainly white-collar workers. All thirteen catering managers of the experimental worksite cafeterias in the study were interviewed (four cafeterias with labeling and education, four with changes in food supply and education, and five with education only), and all nine managers of the experimental supermarkets (four supermarkets with labeling and education and five with education only). All but two of the interviews were recorded on tape and full transcripts were made. (Notes were taken during and immediately after the two interviews -with cafeteria managerswhich were not recorded and these were used instead of transcripts.) The transcripts were divided up 
into small text units, which were coded and categorized by the researcher according to the list of interview topics. After the coding process, the text units were sorted per interview topic. Finally, summary reports were written on each topic. This "cut-and paste” technique is described as a quick, cost-effective and very useful method for analyzing transcripts (Stewart and Shamdasani, 1991).

\section{Results}

General impression

In general, the supermarket and the cafeteria managers had a positive opinion of the intervention programs. The programs were described as clear, professional, informative, well-organized and with a good level of coherence between the various program elements. Some of the supermarket managers remarked that much of the information given in the programs was already familiar. Managers of the worksite cafeterias appreciated the fact that the program was not too obtrusive for customers. However, a few catering managers stated that the intervention could have been more striking (see remarks about program materials).

\section{Opinions on program materials}

Supermarket managers were satisfied with most of the program materials. Most complaints were about the posters. Supermarket chains all have their own standard size for posters, and a standard display system for them. The posters for the programs did not always fit their specific system and they were also too small for most supermarkets. Managers also pointed out that the various posters resembled one another too much. The managers were enthusiastic about the recipe cards and the self-help manual. They considered that the self-help manual contained a lot of interesting, clearly worded information and that it was made of high-quality materials. The fact that customers did not have to pay for the self-help manual was very important for the managers. The contest was also well received by the supermarkets. Almost all supermarkets used the "Next Customer" bars in the first few weeks of the program. Some supermarkets considered that the bars were not heavy enough and that this gave rise to 
problems in use. Because of the intensive use made of the bars, the managers would have preferred them to be made of a more durable material. The buttons were only used for a very short period of time. Some supermarkets did not use the buttons at all. The main reason for this was that neither the managers nor the employees found it practical to wear them. Where labeling was concerned, managers reported the same problem as with the posters. All supermarket chains have their own type of shelving and shelf labeling system. Although the labeling program was adapted to the various systems as much as possible, the labeling system was not always 100\% compatible with the supermarket's own system. Because of this, the labels on some shelves had to be replaced frequently and were not on the shelves all the time. In the case of fresh products, such as meat, it was not always possible to place the labels close to the specific products. Managers also remarked that the labeling was a major deviation from the store's own formula.

Worksite cafeteria managers also commented most on the posters. The posters were not big enough for some cafeterias. Again, the managers pointed out that the different posters resembled one another too much, and they suggested that the colors of the posters should be changed each week. Another remark regarding the posters had to do with the amount of text. Some respondents would have preferred less text and a more prominent place for the pictures on the posters. According to the catering managers, the different table-top information stands also resembled one another too much. Changing the colors each week might have prevented this.

Some managers would have liked table-top information stands constructed of more durable materials. The brochures and self-help manual were well received by the respondents. Buttons were not used, or only for a short period of time. The labels used in the labeling program were easy to understand, but according to some respondents were not striking enough. They could have been larger and also more striking. The same applied to the signs used in the program to increase the range of foods on offer.

\section{Difficulties with program implementation}


In some cases, the program interfered with other campaigns and advertisements at the supermarkets.

The result was that personnel did not always have enough time to put the program materials on display. In addition, there was sometimes insufficient space in the store to display all the materials. However, these problems were solved during the course of the intervention period. Although all the managers mentioned the extra work involved in the program, they agreed that it was kept to a minimum and was not excessive. Another difficulty supermarket managers mentioned during the interviews was that after the first two weeks awareness of the program among both personnel and customers decreased. The availability of time and space was also mentioned by the worksite cafeteria managers. The programs did not take up a lot of time but in all cases they involved extra work on top of the heavy workload that cafeteria personnel already had. One manager felt that the intervention and the worksite cafeteria had conflicting interests: the goal of the program was to discourage people from eating a lot of snacks, whereas the cafeteria’s greatest profits actually came from selling snacks. Cafeterias which wanted to increase their range of low-fat products had difficulty in obtaining them. Their regular suppliers and wholesalers could not always supply the new products, or provide them on a daily basis. In addition, catering managers did not have enough alternatives to choose from, especially where low-fat snacks were concerned. Some catering managers stated that because the range was already extensive, and customers already had a lot of choice, the extra products did not make any difference, and did not attract any attention. In some cases the labeling of snacks was problematical. The fat content of the snacks was sometimes unclear. Furthermore, the managers said that the labeling was the most time-consuming component of the intervention.

\section{Benefits}

Supermarket managers mentioned benefits of the programs both for themselves and for their customers. Where they themselves were concerned, numerous managers mentioned that the programs produced a more positive image for the store because it suggested that they "care" about their customers and provide additional service. Focusing on healthy nutrition is a way to promote their supermarket because they see healthy nutrition as an important issue nowadays. Another benefit for 
the supermarkets was the possibility of higher profits from selling more expensive, healthy products, or from selling a greater number of products, for example ingredients for the recipes promoted on the recipe cards. Benefits mentioned for customers included more information about healthy nutrition, the free self-help manual (which was seen as a reward for the customers), and the variation the programs created in the daily routine of the store. The specific benefits of labeling were increased awareness and the fact that it made labeling easier to select healthy products. However, managers indicated that these benefits mainly applied to customers who were already interested in healthy nutrition, for example people on a diet.

Worksite cafeteria managers did not mention the possibility of greater profits as an important motive. Other than this exception, the other motives mentioned by the supermarket respondents also applied to the worksite cafeterias. The most important benefits for cafeterias, according to their managers, included a positive image for the cafeteria, the provision of a better service, and making people more conscious of their eating habits and the relationship between dietary factors and illness. In addition, worksite respondents mentioned a bonus for their customers' employer: healthy employees were seen as a benefit to the company.

\section{Reactions of customers}

Supermarket managers reported a large number of reactions from customers during the first few weeks of the intervention. Moreover, managers considered that the number of self-help manuals and recipe cards taken by the customers and the number of customers participating in the contest were indicators that the program had had an impact. Some managers felt that the program had contributed to customer satisfaction regarding the store, but others did not see any difference.

Worksite cafeteria managers did not report receiving many reactions at all. In most companies, the number of self-help manuals purchased was not very large, and neither was the number of people 
participating in the contest. Cafeteria managers thought that those who responded were already interested in healthy nutrition before the programs were introduced.

\section{Perceived effects on buying and eating habits}

Most supermarket managers thought that the intervention had positive effects on the buying and eating habits of their customers. Some thought it only had positive effects on specific groups of customers, for example older people. Some managers also believed that although customers learned more about healthy nutrition, this did not alter their actual behavior. Where the specific effects of the labeling component were concerned, they did expect a positive influence on eating habits. According to the managers, labeling could have an influence on buying decisions, particularly when customers have to choose between different brands (with similar prices) of a product.

Most respondents at the worksite cafeterias did not think that people changed their eating habits as a result of the program. Again, some managers thought people learned more about their eating habits and were a little more conscious of them, but did not actually change that behavior. However, there were also respondents who noticed a change in the buying and eating habits at their cafeteria. At a few cafeterias, more vegetable salads were sold after the start of the intervention. Where the cafeterias with the labeling program were concerned, changes were noticed by the managers in sales of low-fat margarine and low-fat meat products. Where snacks were concerned, they only noticed an effect during the first week of labeling. After that, customers very quickly returned to their old habits.

At cafeterias where the range of dishes was increased, the new low-fat desserts sold well. The number of low-fat snacks sold depended on what other snacks were provided on a particular day. Depending on the level of "competition” with other snacks, a low-fat snack might sell better or worse. One catering manager suggested that only replacing existing products by low-fat alternatives would help, as opposed to selling both the fat and the low-fat alternatives. Another manager mentioned that only a 
few low-fat products were added, meaning that this cannot be expected to make a major difference to total consumption.

\section{Discussion}

One of the main goals of the process evaluation described in this article has been to identify possible reasons for the ineffectiveness of the nutrition education program and environmental programs which were developed for supermarkets and worksite cafeterias. Although the managers experienced some practical problems, the degree of implementation of the programs was quite good. In most cases, all the various program elements were implemented in the correct way. However, the labeling was not fully compatible with all the various shelving systems used by the supermarkets. Because of this, implementation of the labeling program was not optimal, which may have led to the labeling being ineffective. However, this applied only to a small proportion of the labels, and it therefore cannot be taken to be the decisive factor in the ineffectiveness of the labeling program. Besides the labels, other program elements, such as the posters, did not always fit in with the standard systems at the supermarkets and the worksite cafeterias. Implementation of the program to increase the range of foods on offer was complicated by the limited number of suitable products available. Products not only had to be low in fat, but also had to be supplied by the regular suppliers of the worksite cafeterias on a daily basis, which was not always possible. As a result, only a small number of new low-fat products and fruit and vegetable options were introduced at the cafeterias. Although most of the new products were well received by the customers, the increase in the range might have been too limited to influence the total consumption of fat, fruit and vegetables at the cafeteria, or even total daily consumption.

The managers confirmed the findings of previous effectiveness studies that the education and labeling programs at worksites were not striking enough to attract a great deal of attention from customers (see also Steenhuis et al., in press (a); Steenhuis et al., in press (b). In accordance with the findings of the 
preliminary study, the managers pointed out that people rush through the cafeteria and do not wish to spend time on nutrition education (Steenhuis, 2001). The time required to use (part of) the intervention programs was kept to a minimum (for example by restricting the amount of information given on the labels) but it may still have been too much for some consumers. These factors may have contributed to the ineffectiveness of the programs. At supermarkets, the programs were more striking. Managers pointed out, however, that the supermarket is a highly competitive environment, with a lot of other advertisements and campaigns vying for attention. This may have resulted in the programs receiving less attention and therefore in their being less effective. It has already been observed that the supermarket is a highly competitive environment and that this leads to problems when exposing people to nutrition education programs and making them aware of them (Ernst et al., 1986; Probart, 1993). Apart from the program materials not attracting a great deal of attention from customers, it could have been that additional program components were needed, especially to increase publicity of the programs and to promote the programs more extensively.

Although a few cafeteria managers thought that people did change their buying and eating habits at the cafeteria as a result of the intervention programs, most managers did not notice any effects on such behavior. This confirms the findings of the effect study at worksite cafeterias, where (except for increased sales of the desserts in the labeling program) no significant changes in sales data could be demonstrated. The supermarket managers did expect the interventions to have positive effects on buying and eating habits. However, no significant effects on eating habits were found in the effect study conducted at supermarkets. Nevertheless, it is possible that the measures in the evaluation studies occured before the effects were evident. Another observation by the managers regarding the effects of the programs was that the program might have had effects on specific groups of customers regarding healthy nutrition. However, additional analysis of data from the effect studies did not reveal an effect for specific subgroups such as older people or people who were in a certain phase of behavioral change. 
Supermarket managers suggested that labeling could influence people’s choice more when choosing between various brands of the same product. Other research also shows that brand-specific labeling might be effective in changing eating habits (Levy, 1985; Muller, 1985). Thus, instead of labeling all brands of a certain type of product as we did in our study, brand-specific labeling could have been more effective. However, we did not use brand-specific labeling for two reasons. Firstly, managers were not very keen on the idea of discriminating between various brands of products because they were afraid of problems with the manufacturers and wholesalers (Steenhuis et al., 2001). This fact decreases the chance of adoption and implementation of a labeling program which uses brand-specific labeling. Second, brand-specific labeling is only feasible when it concerns only a few products, as was the case in the study by Muller (1985), for example. When more product groups are concerned, time considerations mean that it is not feasible to check every single brand of product in all product groups.

In conclusion, this study confirmed some of the explanations for the ineffectiveness of the nutrition education program and environmental components proposed in our earlier studies of the effects of the programs. The present study also identified some additional potential reasons for their ineffectiveness. It therefore provides useful information on the feasibility and effectiveness of such programs at supermarkets and worksite cafeterias. From previous studies into the effectiveness of labeling and increasing the range of healthy products, no or very limited process evaluation data have been published. This is a pity, because this type of studies provide an insight into factors which should be taken into account when developing future nutrition programs to be used in these settings. The present study shows that program materials should be designed in such a way that they are fully compatible with the various systems used at the supermarkets, and they should also be striking enough for customers. This is particularly relevant for the highly competitive supermarket environment. The programs should be promoted intensively. Furthermore, the relevant manufacturers and wholesalers supplying worksite cafeterias should be encouraged to increase their range of suitable low-fat products for sale there. Finally, the feasibility and possible effects of brand-specific labeling should be investigated further. 


\section{References}

Brug, J. (2000) Primaire preventie: computergestuurde voedingsvoorlichting op maat (Primary prevention: Computer-tailored nutrition education). In: Gezondheidsvoorlichting en gedragsverandering; Een planmatige aanpak (Health education and behavioral change; a planned approach). eds. J. Brug, H. Schaalma, G. Kok, R.M. Meertens \& H.T. van der Molen, pp. 161-176, Assen: Van Gorcum/Open Universiteit Nederland.

Ernst, N.D., Wu, M., Frommer, P., Katz, E., Mathews, O., Moskowitz, J., Pinsky, L., Pohl, S., Schreiber, G.B., Sondik, E., Tenney, J., Wilbur, C. \& Zifferblatt, S. (1986) Nutrition education at the point of purchase: The foods for health project evaluated. Prev. Med.. 15, 60-73.

Glanz, K. (1993) Environmental and policy approaches to cardiovascular disease prevention through nutrition. Paper presented at the workshop on environmental and policy approaches to cardiovascular disease prevention. Centers for Disease Control, Atlanta, GA.

Health Council of the Netherlands (2001) Voedingsnormen (Nutrition guidelines). Den-Haag: Gezondheidsraad.

Jeffery, R.W., French, S.A., Raether \& C. Baxter, J.E. (1994) An environmental intervention to increase fruit and salad purchases in a cafeteria. Prev. Med. 23, 788-792.

Kristal, A.R., Goldenhar, L., Muldoon, J. \& Morton, R.F. (1997) Evaluation of a supermarket intervention to increase consumption of fruits and vegetables. Am Health Promotion 11, 422-425. Lang, J.E., Mercer, N., Tran, D. \& Mosca, L. (2000) Use of a supermarket shelf-labeling program to educate a predominately minority community about foods that promote heart health. J. Am. Diet. Assoc.7, 804-809.

Levin, S. (1996) Pilot study of a cafeteria program relying primarily on symbols to promote healthy choices. J. Nutr. Educ. 28, 282-285.

Levy, A.S., Mathews, O., Stephenson, M., Tenney, J.E. \& Schucker, R.E. (1985) The impact of a nutrition education program on food purchases. Journal of Public Policy 4, 1-16.

Mayer, J.A., Brown, T.P., Heins, J.M. \& Bishop, D.B. (1987) A multi-component intervention for 
modifying food selections in a worksite cafeteria. J. Nutr. Educ. 19, 277-280.

Muller, T.E. (1985) Structural information factors which stimulate the use of nutrition information: A field experiment. Journal of Marketing Research 22, 143-157.

Netherlands Bureau for Food and Nutrition. (1992) Praktische Voedingsmiddelengids (Practical food stuff guide). 's Gravenhage: Voedingscentrum.

Netherlands Bureau for Food and Nutrition. (1998) Zo eet Nederland, resultaten van de voedselconsumptiepeiling 1997-1998 (This is how the Netherlands eats: results of the food consumption survey 1997-1998). 's Gravenhage: Voedingscentrum.

Patterson, B.H., Kessler, L.G., Wax, Y., Bernstein, A., Light, L., Midthune, D.N., Portnoy, B., Tenney, J. \& Tuckermanty, E. (1992) Evaluation of a supermarket intervention. The NCI-Giant food eat for health study. Evaluation Review 16, 464-490.

Probart, C.K. (1993) In-store consumer nutrition education utilizing student educators. J. Nutr. Educ. 25, 25-28.

Schmitz, M.F. \& Fielding, J.E. (1986) Point-of-choice nutritional labeling: Evaluation in a worksite cafeteria. J. Nutr. Educ. 18, s65-s68.

Sorenson, G., Morris, D.M., Hunt, M.K., Hebert, J.R., Harris, D.R., Stoddard, A., Ockene, J.K. (1992). Work-site nutrition intervention and employees' dietary habits: The Treatwell program. Am. J. Public Health 6, 214-224.

Steenhuis, I.H.M., Assema, P. van \& Glanz, K. (2001) Strengthening environmental and educational nutrition programmes in worksite cafeterias and supermarkets in the Netherlands. HPI 1, 21-31. Steenhuis, I.H.M., Assema, P. van, Breukelen, G. van \& Glanz, K. (a) (in press, Am. J. Health Promotion) The effectiveness of nutrition education and labeling in Dutch supermarkets. Steenhuis, I.H.M., Assema, P. van, Breukelen, G. van, Glanz, K., Kok, G.J., \& Vries, H. de. (b) (in press, $H P I)$ Evaluation of educational and environmental interventions in Dutch worksite cafeterias. Stewart, D. \& Shamdasani, P.M. (1991) Focusgroups; Theory and practice. Applied Social Research Methods Series, 20. Newbury Park, CA: Sage Publications. 
Willett, W.C. (1994) Diet and Health: What should we eat? Science 264, 532-537. 
Table 1 Main interview topics

- General impression of intervention

- Opinion on various program materials

- Difficulties with implementation

- Perceived benefits of the intervention

- Reactions of customers (enthusiasm, customer satisfaction)

- Perceived effects on buying and eating habits 